\title{
Smoking status and sex as indicators of differences in 2582 obese patients presenting for weight management
}

This article was published in the following Dove Press journal:

Vascular Health and Risk Management

5 May 2012

Number of times this article has been viewed

\section{Michael J Abunassar' \\ George A Wells ${ }^{2}$ \\ Robert R Dent ${ }^{3}$}

'Faculty of Medicine, ${ }^{2}$ Heart Institute, University of Ottawa, Ottawa, Ontario, Canada; ${ }^{3}$ The Ottawa Hospital Weight Management Clinic, Ottawa, Ontario, Canada
Correspondence: Michael J Abunassar University of Ottawa Faculty of Medicine, 45I Smyth Rd, Ottawa, Ontario, Canada KIH 8M5

Tel +l 6137150208

Email mabun032@uottawa.ca
Background: Smoking remains the most common preventable cause of death. Very little tobacco exposure can increase cardiovascular disease risk. The relationship between smoking, sex, and weight remains unclear.

Methods: Between September 1992 and June 2007, 2582 consenting patients starting the Ottawa Hospital Weight Management program were grouped by sex and smoking status. "Former smokers" (771 females, 312 males) had quit for at least 1 year. "Smokers" (135 females, 54 males) smoked $>9$ cigarettes daily. There were 979 females and 331 males who never smoked. Using SAS 9.2 statistical software, the prevalence of coronary artery disease (CAD), type 2 diabetes (T2DM), major depressive disorder (MDD), and medication use among the groups was compared (Chi-square $\left[\chi^{2}\right]$ ). Anthropometric measurements, lipid, glucose and thyroid levels were compared using analysis of variance (ANOVA). Interactions were assessed using 2-way ANOVA analysis for continuous data, and logistic regression for discrete data.

Results: Smokers were more likely to have $\operatorname{MDD}\left(\chi^{2}\right)$, lower high-density lipoprotein levels and higher triglyceride levels than other groups. Former smokers had a greater prevalence of CAD, T2DM on pharmacotherapy, and impaired fasting glucose than other groups. They were also more likely to be taking lipid-lowering agents and antihypertensives $\left(\chi^{2}\right)$. Never smokers had less MDD, CAD, and were less likely to be on antidepressants than the other groups. Males were more likely to have CAD and T2DM than females. Females were more likely to have MDD than males. Interactions between smoking status and sex were found for age, weight, fasting glucose and thyroid-stimulating hormone levels.

Conclusion: Obese never smokers suffer from the fewest chronic diseases. Obese former smokers have a greater prevalence of CAD, T2DM on pharmacotherapy, and impaired fasting glucose than other groups. Thus, clinicians and researchers should avoid combining former smokers with never smokers as "nonsmokers" in research and treatment decisions. The results of this study call for a longitudinal study comparing these groups over the weight management program.

Keywords: smoking status, weight management, obesity

\section{Introduction}

Obesity has reached epidemic proportions worldwide with associated health care costs exceeding \$100 billion annually. ${ }^{1}$ Obesity-associated medical conditions include: type 2 diabetes (T2DM), atherosclerosis, and obstructive sleep apnea. ${ }^{2}$ Obesity is second only to cigarette smoking as the leading preventable cause of death and illness. ${ }^{1}$ Many studies have documented a U- or J-shaped curve for mortality as it relates to body mass index (BMI), with individuals with both low and high BMIs experiencing an increased mortality rate. ${ }^{3}$ Koster et al showed that an especially high mortality risk results when obesity or a large waist circumference is combined with smoking. The investigators 
found that mortality rates increased as BMI increased, and that the rates increased from never smoker to former smoker to current smoker. In addition, obesity combined with current smoking increases circulatory disease mortality by 6 - to 11 -fold for people under the age of 65 years. ${ }^{4}$ Weight control measures may be more prevalent in women than men, ${ }^{5}$ and in a study of body image, men were more likely to be satisfied with their weight than women. ${ }^{6}$ Smoking has been more commonly viewed as a weight control method for women than for men, and used for that purpose. ${ }^{7}$ In a related study of surgical intervention for weight loss, men were more likely to be motivated by medical problems than women. ${ }^{8}$

The Ottawa Hospital-Civic Campus Weight Management clinic provides a unique multidisciplinary weight management program for obese and overweight individuals consisting of a year-long course in lifestyle modification, and total meal replacement typically for the first 12 weeks. ${ }^{9,10}$

In 2001, we published ${ }^{9}$ a study of 968 consecutive patients in this program that examined whether smokers and nonsmokers starting a weight loss program differ in their cardiovascular risk factors. While the smokers had larger waist sizes, higher blood pressures and lower high-density lipoprotein (HDL) levels, both groups derived clear benefit from a $900 \mathrm{kcal}$ meal replacement weight management program. In that study we combined former smokers and never smokers as "nonsmokers". What is unknown is whether the male and female former smokers in the Ottawa Weight Management Clinic population represent a unique population of their own, with unique baseline characteristics at weight management initiation, and as such should be separated from the male and female never smokers as we investigate our program's effects in the future.

Here we examine the baseline characteristics of a larger number of male and female smokers, former smokers and never smokers starting the same multidisciplinary weight management program with a view to perhaps one day tailoring the program to their specific needs. Unlike our previous study, ${ }^{9}$ this one investigates a much broader range of physiological and behavioral variables with plans to look at program effects on all of them in future studies. A better understanding of the relationship between smoking history and sex and the motivation to begin weight management treatment would help physicians to better counsel and tailor weight management programs to specific patient subgroups.

The objectives of the present study include: (1) To investigate the relationship between obese patients' smoking status and their baseline characteristics at the initiation of weight management; (2) To investigate the relationship between obese patients' sex and their baseline characteristics at the initiation of weight management; and (3) To investigate the interaction of obese patients' sex and smoking status as they relate to their baseline characteristics at the initiation of weight management.

\section{Methods}

\section{Criteria for referral to The Ottawa Hospital Weight Management Clinic}

The source population includes: citizens of Ottawa and the surrounding communities in the province of Ontario, Canada. Physicians typically refer patients to the weight management program if they have a BMI of 30 and over, or a BMI of 25 and above with associated T2DM, hypertension, or CAD. These patients have been included in this study.

\section{Procedures}

Patients enter The Ottawa Hospital Weight Management Clinic protocol in closed groups of 23 , meet for weekly interactive teaching sessions for 26 weeks and then monthly for 6 months using Optifast ${ }^{\circledR}$ Behavioral Modules (Nestle Health Science, Vevey, Switzerland). For the first 12 weeks patients are typically on Optifast 900 kilocalorie meal replacement. Data on initial history, physical exam, and laboratory testing protocol are entered in the Ottawa Weight Management Clinic database. ${ }^{9,10}$ Data for this study were extracted from this database, and it includes all of the available information on 2582 patients from September 1992 to June 2007.

At their first visit, patients referred to the Ottawa Weight Management program are asked to fill out a detailed questionnaire concerning smoking status, alcohol use, previous diagnosis of depression by a physician, previous weight-loss attempts, current medications and general health. Please refer to Table 1 for questions relating to smoking behaviours. ${ }^{9,10}$ Patients are weighed, their waist circumference is measured, their BMI is calculated, and their resting blood pressure is recorded. Blood is drawn to assess the patient's lipid profile which includes: HDL, low-density lipoprotein (LDL), triglycerides (TG), apolipoprotein-B (apo-B), thyroxin levels, thyroid-stimulating hormone (TSH) levels, triiodothyronine (T3), glucose levels, insulin levels, and hemoglobin-A1c (Hba-1C). A diagnosis of coronary artery disease (CAD) is based on a documented cardiac event or imaging to prove a cardiac event. A diagnosis of major depressive disorder (MDD), impaired fasting glucose (IFG), type 2 diabetes (T2DM), and hypertension is based on the patient's selfreported past medical history. 
Table I A Sample of the weight management clinic intake questionnaire

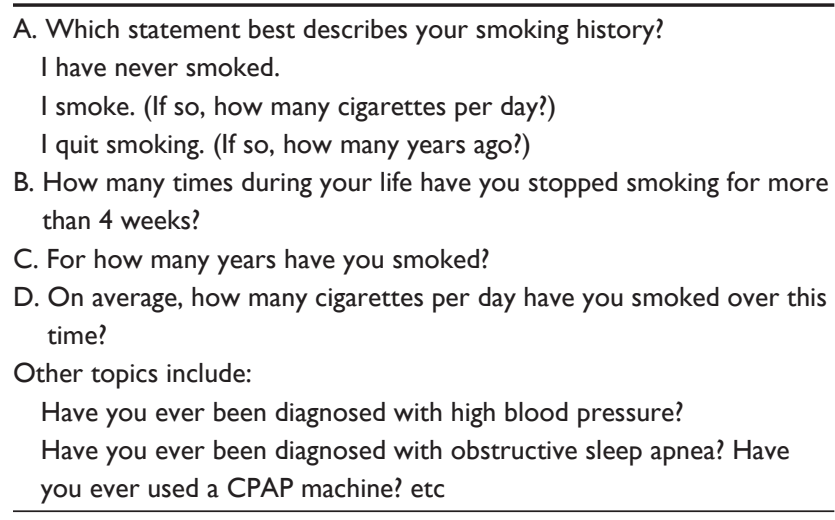

Note: For full detail on the clinic questionnaire, refer to Dent et al. ${ }^{10}$

To better define the groups, and in accordance with Persky et al, ${ }^{11}$ smokers of 10 or more cigarettes per day were used for the present study. Smokers of less than 10 cigarettes per day were not included in the analysis because of the wide variation in cigarette number and the inconsistency of smoking behavior reported in this group. Given that physiologic differences have been found based on the quantity of cigarettes smoked, ${ }^{12}$ heavy smokers (10 or more cigarettes) were separated from the lighter smokers for the purposes of statistical and clinical accuracy. The present study focused on heavy smokers who are at greater health risk than light smokers. Thus, the term "smoker" is defined as an individual smoking at least 10 cigarettes per day or more.

Former smokers were divided into those individuals who quit less than 1 year ago, and those who quit 1 year ago or more as per the literature. ${ }^{5}$ Only the former smokers of 1 year or more were used. According to the literature, ${ }^{13}$ transient weight changes are expected within the first 12 months of smoking cessation, and we chose a minimum of 1 year smoking cessation for a baseline weight measurement as result. Therefore, for the purpose of this study, "former smokers" refers to those individuals who have quit smoking for 1 year or more at the time of program initiation. Please refer to Figure 1 for further details on the population breakdown. The two groups that are found in boxes labeled with an $\mathrm{X}$ above them were excluded from the analysis. Table 2 represents a description of the study population.

With the aim of removing confounding variables when looking for statistical significance, blood pressure data is reported for patients who are not on antihypertensive medications. Similarly, lipid data including: HDL, LDL and TG levels are reported for patients who are not on lipidlowering agents. Glucose and Hbalc data is reported for patients not being treated for T2DM either with medication or insulin. TSH and T3 data is reported for patients not on T3 supplementation.

\section{Ethics}

Ethics approval was obtained by way of formal application to the Ottawa Hospital Research Ethics Boards. Patients consented to their data being included for the purpose of this research. Written informed consent was obtained from all participants. Every patient whose data is provided in this study agreed to his/her data being published. In addition, we have no conflicts of interest to declare.

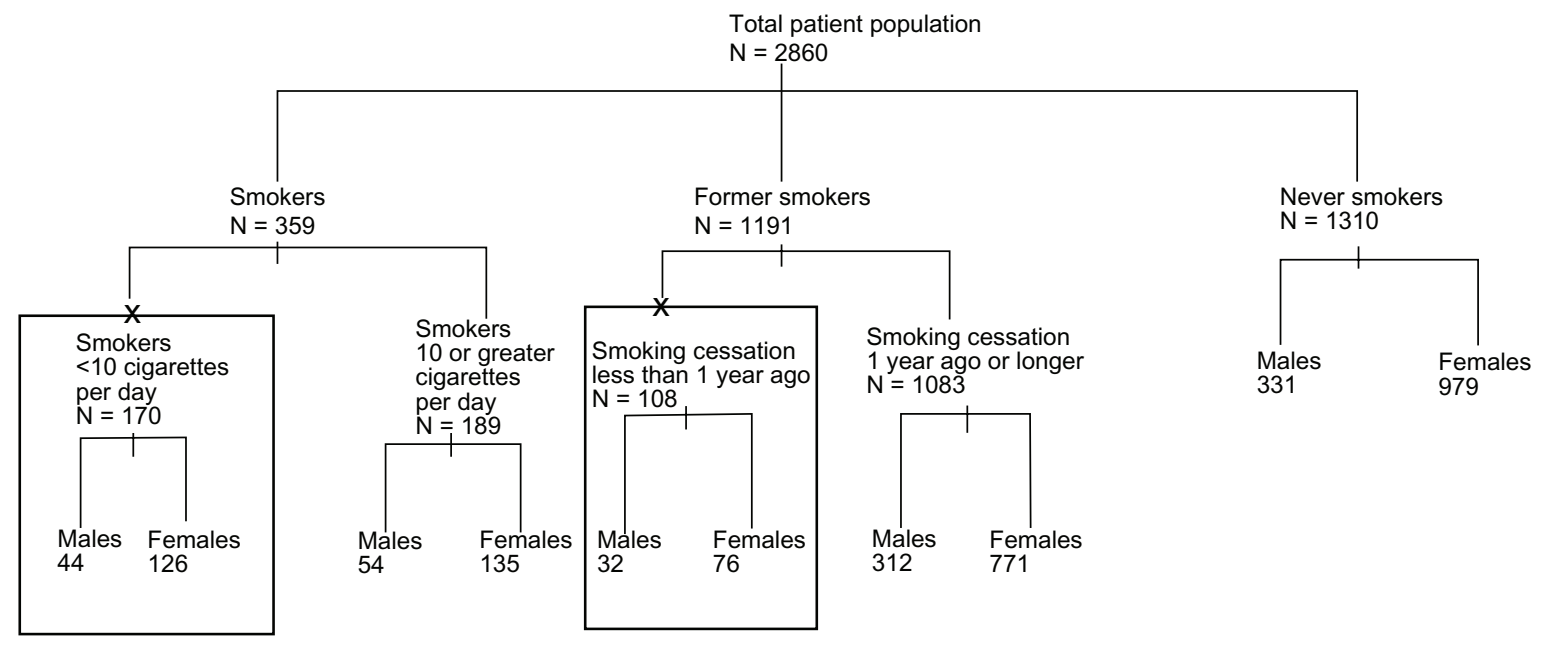

Figure I Division of the patient population based on smoking history and sex.

Notes: Patients were grouped according to their smoking status and then by their sex. Patient groups that have been placed within the two boxes labelled with X's were not included in the analysis for reasons explained in the methods section. X-indicates removed from study analysis. 
Table 2 Comparing male and female smokers, former smokers, and never smokers, across continuous physiological variables at program initiation

\begin{tabular}{|c|c|c|c|c|c|c|}
\hline \multirow[t]{4}{*}{ Smoking Status } & \multicolumn{6}{|l|}{ Sex } \\
\hline & \multirow{2}{*}{\multicolumn{3}{|c|}{$\begin{array}{l}\text { Female } \\
N=1885\end{array}$}} & \multirow{2}{*}{\multicolumn{3}{|c|}{$\begin{array}{l}\text { Male } \\
N=697\end{array}$}} \\
\hline & & & & & & \\
\hline & $\begin{array}{l}\text { Smoker } \\
N=135\end{array}$ & $\begin{array}{l}\text { Former smoker } \\
\mathbf{N}=77 \text { I }\end{array}$ & $\begin{array}{l}\text { Never smoker } \\
\mathrm{N}=979\end{array}$ & $\begin{array}{l}\text { Smoker } \\
N=54\end{array}$ & $\begin{array}{l}\text { Former smoker } \\
\mathbf{N}=312\end{array}$ & $\begin{array}{l}\text { Never smoker } \\
\mathbf{N}=331\end{array}$ \\
\hline \multirow[t]{2}{*}{ Age* (SD) } & $5 \mathrm{I} .8(10.7)$ & $57.1(10.7)$ & $52.3(12.0)$ & $50.7(11.4)$ & $60.2(9.7)$ & $51.8(11.2)$ \\
\hline & 135 & $77 I$ & 979 & 54 & $3 / 2$ & 331 \\
\hline \multirow[t]{2}{*}{ BMI (SD) } & $463(6.7)$ & $45.0(6.0)$ & $44.2(6.0)$ & $55.1(7.6)$ & $53.3(6.4)$ & $53.8(7.1)$ \\
\hline & 123 & 701 & 899 & 49 & 270 & 307 \\
\hline \multirow[t]{2}{*}{ Weight* (Ibs) (SD) } & $249.8(5 I .4)$ & $245.9(49.3)$ & $242.6(46.9)$ & $323.5(69.1)$ & $302.4(62.5)$ & $309.7(70.1)$ \\
\hline & 135 & 771 & 979 & 54 & 312 & 331 \\
\hline \multirow[t]{2}{*}{ WC (inches) (SD) } & $42.0(7.8)$ & $41.7(8.2)$ & $4 I . I(7.6)$ & $45.8(9.5)$ & $43.8(8.9)$ & $44.9(9.6)$ \\
\hline & 135 & 769 & 976 & 54 & $3 / 2$ & 331 \\
\hline \multirow[t]{2}{*}{ Systolic BP (mmHg) (SD) } & $128.9(20.6)$ & I30.6 (14.8) & $129.7(13.9)$ & I34.8 (| I.7) & $136.7(\mid 1.1)$ & I35.7 (29.3) \\
\hline & 75 & 366 & 501 & 31 & 130 & 183 \\
\hline \multirow[t]{2}{*}{ Diastolic BP (mmHg) (SD) } & $80.6(11.5)$ & $81.7(8.9)$ & $81.5(7.6)$ & $82.8(12.0)$ & 84.4 (II.I) & $84.9(7.8)$ \\
\hline & 75 & 366 & 501 & 31 & 130 & 183 \\
\hline \multirow[t]{2}{*}{ Glucose* (mmol/L) (SD) } & $5.5(1.4)$ & $5.5(1.2)$ & $5.3(1.1)$ & $5.5(1.3)$ & $6.0(1.7)$ & $5.5(1.3)$ \\
\hline & 105 & 589 & 790 & 39 & 218 & 256 \\
\hline \multirow[t]{2}{*}{$\mathrm{TSH}^{*}(\mathrm{mU} / \mathrm{L})(\mathrm{SD})$} & $2.2(1.5)$ & $2.6(3.4)$ & $2.4(1.7)$ & $2.0(1.6)$ & $2.2(1.7)$ & $2.3(1.3)$ \\
\hline & 95 & 535 & 731 & 43 & 261 & 272 \\
\hline
\end{tabular}

Notes: Mean values are presented \pm standard deviation (SD). Waist circumference (WC) in inches, blood pressure (BP) measured in mmHg, thyroid-stimulating hormone (TSH) ( $\mathrm{mU} / \mathrm{L}$ ), fasting blood glucose (Glucose) ( $\mathrm{mmol} / \mathrm{L})$. BP reported for patients who are not on medications which alter it. TSH values are presented for patients not on thyroid-hormone replacement. Glucose data is presented for patients not being treated for T2DM. *Interactions were found for smoking status and sex with respect to age of program initiation, baseline weight, fasting blood glucose and TSH in patients not on T3/T4 supplementation $(P<0.05)$. All values in italics represent the number of patients for which a result was available.

Abbreviation: BMI, body mass index; T2DM, type 2 diabetes mellitus.

\section{Statistical analysis}

Using SAS software (v 9.2; SAS Institute, Cary, NC), statistical analysis was performed on the data, namely oneway ANOVA analysis, followed by Tukey's HSD post-hoc analysis for the continuous data. Chi-square analysis was employed for the discrete data, using Fisher's exact test in the instance of an expected value below $5 .{ }^{14}$ For continuous data, $2 \times 2$ interactions were studied using two-way ANOVA for items such as: age, waist circumference, and TSH data for which a $P$-value $<0.05$ was accepted as statistically significant. Logistic regression was used for the discrete data which include: a diagnosis of $\mathrm{CAD}$, or MDD, for which a $P$-value $<0.05$ was accepted as statistically significant.

\section{Results}

The flow diagram for this population is given in Figure 1. Never smokers was the most common grouping, followed by former smokers, and then smokers. Each category appeared representative of the overall 2.7:1 female:male ratio of the entire population. The ratio of smokers of less than 10 cigarettes per day to smokers of 10 cigarettes a day or more was approximately $1: 1$, while the population of former smokers was approximately $90 \%$ quitters of 1 year or more. The mean number of years quit for males was 15.0 years, and for females 13.2 years.
A description of the baseline variables from our study group of 2582 patients based on sex and smoking status is presented in Table 2 . A $2 \times 2$ ANOVA analysis of age, weight, fasting blood glucose and TSH with sex and smoking revealed interactions $(P<0.05)$. With respect to age, the mean age for the population was $54.6 \pm 11.5$ years. Male and female smokers were the youngest in the group, whereas male and female former smokers were the eldest. The mean weight for the male population was $307 \pm 66.9$ pounds, while the mean weight for the female population was $244.4 \pm 48.3$ pounds. Male and female smokers were the heaviest for their particular sex (male mean $323.5 \pm 69.1$ pounds, female mean $249.8 \pm 51.4$ pounds), whereas never smokers were the lightest females (242.6 \pm 46.9 pounds), and former smokers were the lightest males (302.5 \pm 62.5 pounds). The glucose data was restricted to patients not being treated for T2DM, and male former smokers had the highest fasting blood glucose $(6.0 \pm 1.7 \mathrm{mmol} / \mathrm{L})$, yet the mean was within the normal range. Extreme fasting glucose levels for "nondiabetic" male former smokers crossed the normal range. Male smokers appeared to have the lowest TSH levels $(2.0 \pm 1.6 \mathrm{mU} / \mathrm{L})$, while female smokers had the highest TSH levels $(2.2 \pm 1.5 \mathrm{mU} / \mathrm{L})$. The mean blood pressure for the entire population is $135.4 \mathrm{mmHg}( \pm 17.2) / 83.2 \mathrm{mmHg}$ 
$( \pm 8.5)$, however this is for the patients who were not on blood pressure altering medications.

Smokers had the largest waist circumferences (males mean $45.8 \pm 9.5$ inches, females mean $42.0 \pm 7.8$ inches) and they had the highest triglyceride levels after removal of patients on lipid lowering drugs (mean $2.0 \pm 1.0$ ) (Table 3). Former smokers had significantly higher total cholesterol $(5.4 \pm 1.0 \mathrm{mmol} / \mathrm{L})$, and HDL levels $(1.2 \pm 0.2 \mathrm{mmol} / \mathrm{L})$ than smokers. Former smokers had higher LDL levels $(3.4 \pm 0.8 \mathrm{mmol} / \mathrm{L})$ than never smokers. Smokers had higher TG levels $(2.0 \pm 1.0 \mathrm{mmol} / \mathrm{L})$ than former smokers and never smokers.

Former smokers in the treatment-seeking population had an increased prevalence of impaired fasting glucose, were more likely to have medically treated type 2 diabetes, and to be on antihypertensive medication than the other groups as shown by Chi-square test (Table 4A). Never smokers were less likely to use alcohol in excess of the suggested amounts, and were less likely to be on lipid-lowering agents and antidepressants than the other groups as shown by Chisquare test.

Men in the treatment-seeking population had an increased prevalence of T2DM (treated and untreated, Table 4B) compared to women. Men were more likely to be taking lipid-lowering medications, antihypertensives, exceeding the suggested weekly alcohol intake, and to have a diagnosis of CAD than women. Women were more likely to be diagnosed with depression, to be taking antidepressants, and to be on T3 or T4 supplements than men, as shown by Chi-square test.

After Chi-square analysis of the data in Table 4A and $\mathrm{B}$ was performed, logistic regression was performed to investigate any significant $2 \times 2$ interactions of smoking status with sex for each of the discrete variables presented. All $P$-values obtained from this analysis were greater than 0.05 , and as such no $2 \times 2$ interactions were noted.

Males had greater waist circumferences $(53.7 \pm 6.9$ inches versus $44.7 \pm 6.1$ inches) and higher blood pressure values for both systolic (135.6 $\pm 24.3 \mathrm{mmHg}$ versus $129.8 \pm 15.4 \mathrm{mmHg})$, and diastolic $(84.5 \pm 9.6 \mathrm{mmHg}$ versus $81.5 \pm 8.5 \mathrm{mmHg})$, had worse lipid profiles, and were at a higher risk for T2DM than females (Table 5). Obese females were more likely to suffer from decreased T3 production than males. Known sex differences such as females with higher HDL levels than men $(1.3 \pm 0.3 \mathrm{mmol} / \mathrm{L}$ versus $1.0 \pm 0.2 \mathrm{mmol} / \mathrm{L})$, and men with higher TG levels $(2.04 \pm 1.1 \mathrm{mmol} / \mathrm{L}$ versus $1.7 \pm 0.9 \mathrm{mmol} / \mathrm{L})$ were also evident. ${ }^{15}$

Table 3 Comparing smokers (S), former (FS), and never smokers (NS) across continuous physiological variables at program initiation

\begin{tabular}{|c|c|c|c|c|}
\hline Smoking status & $\begin{array}{l}\text { Smoker } \\
N=189\end{array}$ & $\begin{array}{l}\text { Former smoker } \\
N=1083\end{array}$ & $\begin{array}{l}\text { Never smoker } \\
N=1310\end{array}$ & Description \\
\hline \multirow[t]{2}{*}{ WC (inches) (mmHg) (SD)* } & $48.8(8.0)$ & $47.3(7.2)$ & $46.6(7.57)$ & $\mathrm{S}>\mathrm{FS}, \mathrm{S}>\mathrm{NS}$ \\
\hline & 170 & 971 & 1206 & \\
\hline \multirow[t]{2}{*}{ Systolic BP (mmHg) (SD) } & I30.6 (I8.6) & $131.6(16.6)$ & $131.3(19.5)$ & \\
\hline & 106 & 497 & 683 & \\
\hline \multirow[t]{2}{*}{ Diastolic BP (mmHg) (SD) } & $81.2(11.6)$ & $82.4(9.6)$ & $82.4(7.8)$ & \\
\hline & 106 & 497 & 683 & \\
\hline \multirow{2}{*}{ Total chol (SD)* } & $5.2(1.0)$ & $5.4(1.0)$ & $5.20(0.96)$ & $\mathrm{FS}>\mathrm{S}$ \\
\hline & 132 & 770 & 1019 & \\
\hline \multirow[t]{2}{*}{$\mathrm{HDL} \pm(\mathrm{mmol} / \mathrm{L})(\mathrm{SD})^{*}$} & I.I (0.3) & I.2(0.3) & $1.2(0.3)$ & $\mathrm{FS}>\mathrm{S}$ \\
\hline & 132 & 764 & 1004 & \\
\hline \multirow[t]{2}{*}{ TG* $\pm(m m o l / L) ~(S D)$} & $2.0(1.0)$ & $1.8(1.0)$ & $1.7(0.9)$ & $\mathrm{S}>\mathrm{FS}, \mathrm{S}>\mathrm{NS}$ \\
\hline & 134 & 759 & 1014 & \\
\hline \multirow[t]{2}{*}{ LDL* (mmol/L) (SD) } & $3.3(0.8)$ & $3.4(0.8)$ & $3.2(0.8)$ & $\mathrm{FS}>\mathrm{NS}$ \\
\hline & 126 & 727 & 978 & \\
\hline \multirow[t]{2}{*}{ ApoB* (g/L) (SD) } & I.I (0.3) & I.I (0.3) & $\mathrm{I} .0(0.2)$ & $\mathrm{FS}>\mathrm{NS}$ \\
\hline & 29 & 434 & 648 & \\
\hline \multirow[t]{2}{*}{ Hba-Ic (SD) } & $0.06(0.006)$ & $0.06(0.08)$ & $0.06(0.01)$ & \\
\hline & 42 & 270 & 376 & \\
\hline \multirow[t]{2}{*}{ T3 (pmol/L) (SD) } & $4.1(0.80)$ & $4.0(0.7)$ & $4.0(0.8)$ & \\
\hline & 77 & 558 & 718 & \\
\hline
\end{tabular}

Notes: Mean values are presented \pm standard deviation (SD). *Indicates a significant difference at $P<0.05$. Waist circumference (WC) in inches, blood pressure (BP) in $\mathrm{mmHg}$, high-density lipoprotein (HDL) (mmol/L), triglycerides (TGs) (mmol/L), low-density lipoprotein (LDL) (mmol/L), apo-lipoprotein-B (Apo-B) (g/L), hemoglobin-alc (Hba-lc), Triiodothyronine (T3) (pmol/L). The description column explains which groups have a higher value $(>$ ) for the particular variable studied. BP data is reported for patients who are not on medications which alter it. Lipid data is reported for patients who are not on lipid-lowering agents. Glucose and Hba-Ic data is reported for patients not being treated for T2DM. T3 data is reported for patients on thyroid-hormone supplementation. All values in italics represent the number of patients for which a result was available. 
Table 4A Comparing smokers, former smokers, and never smokers across discrete variables at program initiation

\begin{tabular}{|c|c|c|c|}
\hline & \multicolumn{3}{|l|}{ Variable } \\
\hline & $\begin{array}{l}\text { Smoker } \\
N=189 \text { (\%) }\end{array}$ & $\begin{array}{l}\text { Former } \\
\text { smoker }\end{array}$ & $\begin{array}{l}\text { Never } \\
\text { smoker }\end{array}$ \\
\hline & & $N=1083(\%)$ & $N=1310(\%)$ \\
\hline IFG* & 1.6 & 5.9 & 4.4 \\
\hline T2DM not on meds* & 6.4 & 6.1 & 3.3 \\
\hline T2DM on meds* & 5.8 & 14.0 & 7.6 \\
\hline On lipid-lowering agents* & 13.3 & 15.4 & 9.7 \\
\hline On antihypertensives* & 20.6 & 35.1 & 26.9 \\
\hline Alcohol > suggested* & 8.5 & 8.4 & 3.1 \\
\hline Dx of CAD* & 2.1 & 8.6 & 3.2 \\
\hline Dx of depression & II.I & 6.9 & 7.1 \\
\hline On antidepressants* & 34.4 & 29.2 & 23.9 \\
\hline On T4 supplementation & 12.7 & 15.3 & 12.5 \\
\hline
\end{tabular}

Notes: Chi-square analysis $\left(\chi^{2}\right)$ was performed, and $P$-values of $<0.05$ accepted at significant $(*)$. Impaired fasting glucose (IFG), diabetes (DM), suggested alcohol intake for a male is no more than 14 drinks per week, and no more than II for a women. Coronary artery disease (CAD) was determined based on the diagnosis of a cardiac event or imaging to prove a cardiac event. All data is presented as a \% of the population exhibiting the particular trait.

\section{Discussion}

Separating patients entering the Ottawa Weight Management Clinic program into groups based on smoking status and sex did reveal significant baseline differences. Smokers were more likely to have a diagnosis of MDD, lower HDL and higher triglyceride levels than the other groups. Former smokers had a greater prevalence of CAD, T2DM on pharmacotherapy, and impaired fasting glucose than smokers and never smokers. They were also more likely to be taking lipid-lowering agents (LLAs), and to be on antihypertensives than the other two groups as well. Former smokers who are not taking LLAs had higher HDL levels than smokers. The never smokers group had fewer MDD and CAD diagnoses, and they were less likely to be on antidepressants than the other two groups. Males were more likely to be suffering from CAD and T2DM than females. Females were more likely to suffer from MDD than males. Interactions between smoking status and sex were found for age, weight, fasting blood glucose and TSH levels.

The results obtained from our study population do not completely agree with the literature, or expectation. In a US study, smokers weighed on average $3 \mathrm{~kg}$ less than nonsmokers, and smoking cessation can result in a weight gain of $6 \mathrm{~kg}$ on average over a 1-year period. ${ }^{6}$ This was not found to be the case in our study population. However, our study population does not represent a random sample, as patients were selected based on a unique treatment criteria as described in our study methods. Smokers were found to be
Table 4B Comparing males and females across discrete variables at program initiation

\begin{tabular}{lll}
\hline & \multicolumn{2}{l}{ Variable } \\
\cline { 2 - 3 } & Males & Females \\
& $\mathbf{N}=\mathbf{6 9 7}(\%)$ & $\mathbf{N}=1885$ (\%) \\
\hline IFG* & 6.0 & 4.4 \\
T2DM not on meds* & 6.5 & 4.0 \\
T2DM on meds* & 15.2 & 8.3 \\
On lipid-lowering agents* & 20.3 & 9.4 \\
On antihypertensives* & 41.2 & 25.7 \\
Alcohol > suggested* & 10.1 & 4.1 \\
Dx of CAD* & 12.1 & 2.9 \\
Dx of depression & 5.3 & 8.1 \\
On antidepressants* & 18.7 & 29.9 \\
On T4 supplementation & 5.6 & 16.7
\end{tabular}

Notes: Chi-square analysis $\left(\chi^{2}\right)$ was performed, and $P$-values of $<0.05$ accepted at significant $(*)$. Impaired fasting glucose (IFG), diabetes (DM), suggested alcohol intake for a male is no more than 14 drinks per week, and no more than II for a women. Coronary artery disease (CAD) was determined based on the diagnosis of a cardiac event or imaging to prove a cardiac event. All data is presented as a \% of the population exhibiting the particular trait.

the heaviest group - which may represent patients for whom smoking did not serve as a good weight control measure. Therefore, the results of this study are meant to be used by clinicians whose patients reflect the demographics in our study population. In fact, female former smokers were the lightest group in the study population. Lerman et al ${ }^{17}$ suggest that the increase in body weight that occurs following smoking cessation is related to increases in food reward and food reward is determined at least in part by genetic factors. ${ }^{16}$ However, since we only used former smokers who had quit for a minimum of 1 year, the female former smokers may represent a group of people who have already been consciously monitoring their weight to an extent prior to program entry, and have been enrolled in the program for additional assistance.

The association between serum lipids increase and BMI increase is significant and strong, and is greater for men than for women. ${ }^{17}$ Smokers had elevated triglyceride levels which is consistent with the literature, ${ }^{12}$ however, it must be noted that patients requiring lipid management medications were removed from the analysis. In addition, the literature suggests that smoking leads to increased waist circumference, and smokers were found to have the largest waist circumference in this population. ${ }^{18}$ Former smokers have a greater prevalence of hypertension, history of cardiovascular disease, alcohol overuse, and T2DM than never smokers. Furthermore, there is an increased prevalence of former smokers with impaired fasting glucose which may be related to insulin resistance secondary 
Table 5 Comparing males and females across continuous physiological variables at program initiation

\begin{tabular}{|c|c|c|c|}
\hline & \multicolumn{2}{|l|}{ Sex } & \multirow[t]{2}{*}{ Description } \\
\hline & $\begin{array}{l}\text { Male } \\
\mathbf{N}=697\end{array}$ & $\begin{array}{l}\text { Female } \\
N=1885\end{array}$ & \\
\hline $\begin{array}{l}\text { Systolic BP } \\
(\mathrm{mmHg})(\mathrm{SD})^{*}\end{array}$ & $\begin{array}{l}\text { I } 35.6(24.3) \\
344\end{array}$ & $\begin{array}{l}129.8(15.4) \\
942\end{array}$ & Males $>$ Females \\
\hline $\begin{array}{l}\text { Diastolic BP } \\
(\mathrm{mmHg})(\mathrm{SD})^{*}\end{array}$ & $\begin{array}{l}84.5(9.6) \\
344\end{array}$ & $\begin{array}{l}81.5(8.5) \\
942\end{array}$ & Males $>$ Females \\
\hline $\begin{array}{l}\text { Total chol } \\
(\mathrm{mmol} / \mathrm{L})(\mathrm{SD})^{*} \\
\text { ApoB }(\mathrm{g} / \mathrm{L})(\mathrm{SD})\end{array}$ & $\begin{array}{l}5.2(1.0) \\
467 \\
1.1(0.3) \\
286\end{array}$ & $\begin{array}{l}5.32(1.0) \\
1454 \\
1.1(0.3) \\
825\end{array}$ & Females $>$ Males \\
\hline Hba-Ic (SD) & $\begin{array}{l}0.06(0.0091) \\
192\end{array}$ & $\begin{array}{l}0.06(0.0060) \\
496\end{array}$ & \\
\hline $\begin{array}{l}\text { T3 (pmol/L) } \\
\text { (SD) }\end{array}$ & $\begin{array}{l}4.2(0.74) \\
405\end{array}$ & $\begin{array}{l}3.9(0.74) \\
948\end{array}$ & Males $>$ Females \\
\hline $\begin{array}{l}\mathrm{LDL} \\
(\mathrm{mmol} / \mathrm{L})(\mathrm{SD})^{*}\end{array}$ & $\begin{array}{l}3.2(0.79) \\
439\end{array}$ & $\begin{array}{l}3.3(0.84) \\
1392\end{array}$ & Females $>$ Males \\
\hline Known sex diff & ences & & \\
\hline $\begin{array}{l}\text { WC } \\
\text { (inches) (SD)* }\end{array}$ & $\begin{array}{l}53.7(6.9) \\
62.6\end{array}$ & $\begin{array}{l}44.7(6 . I) \\
I 72 I\end{array}$ & Males $>$ Females \\
\hline $\begin{array}{l}\mathrm{HDL} \\
(\mathrm{mmol} / \mathrm{L})(\mathrm{SD})^{*}\end{array}$ & $\begin{array}{l}1.0(0.2) \\
461\end{array}$ & $\begin{array}{l}1.3(0.3) \\
1439\end{array}$ & Females $>$ Males \\
\hline $\begin{array}{l}\text { TGs } \\
(\mathrm{mmol} / \mathrm{L})(\mathrm{SD})^{*}\end{array}$ & $\begin{array}{l}2.04(1.1) \\
462\end{array}$ & $\begin{array}{l}1.70(0.9) \\
1445\end{array}$ & Males $>$ Females \\
\hline
\end{tabular}

Notes: Mean values are presented $+/-$ standard deviation (SD). *Indicates a significan difference at $P<0.05$. Waist circumference (WC) in inches, blood pressure (BP) measured in $\mathrm{mmHg}$, high-density lipoprotein (HDL) ( $\mathrm{mmol} / \mathrm{L})$, triglycerides (TGs) (mmol/L), low-density lipoprotein (LDL) (mmol/L), apo-lipoprotein-B (Apo-B) $(\mathrm{g} / \mathrm{L})$, Hemoglobin-alc (Hbalc), triiodothyronine (T3) (pmol/L), total cholesterol (total chol) $(\mathrm{mmol} / \mathrm{L})$. The description column explains which groups had a higher value $(>)$ for the particular variable studied. BP data is reported for patients who are not on medications which alter it. Lipid data is reported for patients who are not on lipid lowering agents. Glucose, Insulin and $\mathrm{Hbalc}$ data is reported for patients not being treated for T2DM. T3 data is represented for patients not on thyroid-hormone supplementation. All values in italics represent the number of patients for which a result was available.

to adipose deposition around the waist from years of heavy smoking, or from increased weight gain post-smoking cessation. According to the Framingham study, the life expectancy of obese smokers is 13 years less than normal weight nonsmokers. There is also evidence to support the hypothesis that smoking affects body fat distribution associated with central obesity and insulin resistance. ${ }^{19}$

The former smoker group may represent a population who are seeking to reform their lives after a shocking medical event such as a heart attack, or the diagnosis of T2DM. The literature shows that smoking cessation yields substantial health benefits. ${ }^{1,17}$ Never smokers appear to suffer from fewer chronic illnesses than both smokers and former smokers. Never smokers are also less likely to be on antidepressant medication than smokers and former smokers. This may be explained by further research in the common dopamine pathways of addiction to smoking and addiction to food and the relationship of mood with addiction. ${ }^{20}$
Males in the obesity treatment program are more likely to be suffering from chronic illnesses like diabetes and coronary artery disease. This may suggest that men require adverse health events as motivators for weight management. As stated previously, men are also more likely to seek surgery for weight loss for medical reasons than women. ${ }^{8}$ Women may be more concerned with body image. ${ }^{6}$ The increased prevalence of depression and antidepressive medication use among women may reflect a negative body image, or a possible explanation for disordered eating patterns.

Interactions between smoking status and sex were found for age at program initiation, weight, fasting blood glucose and TSH levels. Therefore, physician counseling about weight management should be responsive to the sex and smoking status combination of each patient. For example, a young female former smoker may be seeking to improve her body image after weight gain from smoking cessation. An older male smoker may require weight management to treat his T2DM, which may be the most important therapeutic task for this patient group. ${ }^{21}$

A limitation of this study is the small number of male smokers $(n=54)$ and female smokers $(n=135)$, especially those with proper medical management. The data on smoking status was based on self-report questionnaires which are subject to numerous forms of responder bias and recollection errors. In addition, we did not divide former smokers into former light, and former heavy smokers since many former smokers had great difficulty remembering if they smoked nine cigarettes a day or ten or more. We did not study the former smokers who had quit less than 1 year prior to program initiation. While other studies have removed them as well, it could further our understanding of recent versus nonrecent quitters. The number of years that former smokers smoked was not compared against the number of years the current smokers have been smoking. However, there are some reversible effects of smoking on lipid metabolism post-smoking cessation which may also confound the analysis. ${ }^{22}$

Future studies will aim to identify whether smoking cessation and weight management can be tackled simultaneously. For example, Persky et al suggest that eating and smoking may have shared functional or topographic features as adherence to smoking cessation and dietary plans declined over time and co-varied throughout their study. ${ }^{11}$ According to Wee et al, adults younger than 30 years are more likely to smoke if they are trying to lose weight. However, smokers of all ages who are trying to lose weight are more likely to want to stop smoking. ${ }^{23}$ 
There are certainly clear clinical implications of this study. Physicians considering weight management for their patients should review the individual's experience with smoking, their sex, age, etc. Knowledge of previous health scares, weight gain due to smoking cessation attempts, increased cardiovascular risk due to smoking and obesity are all important factors that a physician should consider when referring to weight management programs. Given that the obese former smokers suffer from more chronic diseases than never smokers, even with a mean cessation period of $10+$ years, there is a danger in researchers and physicians combining never smokers with former smokers under the common label of "nonsmokers" in treatment decisions, or study design. A "nonsmokers" category which was created in Wilson et $\mathrm{al}^{9}$ would neglect the significant differences we have identified between former smokers and never smokers. The results of this study call for a longitudinal study comparing male smokers, male former smokers, male never smokers, female smokers, female former smokers and female never smokers on the 1-year-long weight management clinic program to see if the baseline differences identified here predict differences in program outcomes. If outcome differences do exist, there could be a strong argument for tailoring weight management programs to these unique groups.

\section{Disclosure}

The authors report no conflicts of interest in this work.

\section{References}

1. Greenberger NJ, Blumberg RS, Burakoff R, editors. Current Diagnosis and Treatment in Gastroenterology, Hepatology and Endoscopy. New York, NY: McGraw Hill; 2009:210-212.

2. Greenstein B, Wood D. The Endocrine System at a Glance. Maiden, MA: Blackwell Publishing Ltd; 2008:98-101.

3. Allison D, Faith MS, Heo M, Kotler DP. Hypothesis concerning the $\mathrm{U}$-shaped relation between body mass index and mortality. Am J Epidemiol. 1997;146(4):339-349.

4. Koster A, Leitzmann MF, Schatzkin A, et al. The combined relations of adiposity and smoking on mortality. Am J Clin Nutr. 2008;88(5): 1206-1212.

5. Neumak-Sztainer D, Sherwood NE, French SA, Jeffery RW. Weight control behaviours among men and women: cause for concern? Obes Res. 1999;7(2):179-188.

6. McElhone S, Kearney JM, Giachetti I, Zunft HJ, Martinez JA. Body image in relation to recent weight changes and strategies for weight loss in a nationally representative sample in the European Union. Public Health Nutr. 1999;2(1A):143-151.

Vascular Health and Risk Management

\section{Publish your work in this journal}

Vascular Health and Risk Management is an international, peerreviewed journal of therapeutics and risk management, focusing on concise rapid reporting of clinical studies on the processes involved in the maintenance of vascular health; the monitoring, prevention and treatment of vascular disease and its sequelae; and the involvement of
7. Waldron I. Patterns and causes of gender differences in smoking. Soc Sci Med. 2002;32(9):989-1005.

8. Libeton M, Dixon JB, Laurie C, O'Brien PE. Patient motivation for bariatric surgery: characteristics and impact on outcomes. Obes Surg. 2004;14(3):392-398.

9. Wilson K, Clark H, Hotz S, Dent R. Impact of smoking status on weight loss and cardiovascular risk factors. J Epidemiol Community Health. 2001;55(3):213-214.

10. Dent RM, Penwarden RM, Harris N, Hotz SB. Development of patient-centered software for a weight-management clinic. Obes Res. 2002;10(7):651-656.

11. Persky I, Spring B, Vander Wal JS, Pagoto S, Hedeker D. Adherence across behavioural domains in treatment promoting smoking cessation plus weight control. Health Psychol. 2005;24(2):153-160.

12. Craig WY, Palomaki GE, Haddow JE. Cigarette smoking and serum lipid and lipoprotein concentrations: an analysis of published data. $B M J$. 1989;298(6676):784-788.

13. Aubin HJ, Berlin I, Smadja E, West R. Factors associated with higher body mass index, weight concern and weight gain in a multinational cohort study of smokers intending to quit. Int $J$ Environ Res Public Health. 2009;6(3):943-957.

14. Gravetter FJ. Study Guide for Gravetter and Wallnau's Essentials of Statistics for the Behavioral Sciences. 5th Edition. New York, NY: Thomson Learning; 2000.

15. MacLean DR, Petrasovits A, Connelly PW, Joffres M, O'Connor B, Little JA. Canadian Heart Health Surveys 1986-1992. Plasma lipids and lipoprotein reference values, and the prevalence of dyslipoproteinemia in Canadian adults. Canadian Heart Health Surveys Research Group. Can J Cardiol. 1999;15(4):434-444.

16. Lerman C, Berrettini W, Pinto A, et al. Changes in food reward following smoking cessation: a pharmacogenetic investigation. Psychopharmacology (Berl). 2004;174(4):571-577.

17. Wilsgaard T, Arnesen E. Change in serum lipids and body mass index by age, gender, and smoking status: the Tromso study 1986-1995. Ann Epidemiol. 2004;14(4):265-273.

18. FilozofC, Fernandez Pinilla MC, Fernandez-Crux A. Smoking cessation and weight gain. Obes Rev. 2004;5(2):95-103.

19. Chiolero A, Faeh D, Paccaud F, Cornuz J. Consequences of smoking for body weight, body fat distribution, and insulin resistance. Am J Clin Nutr. 2008;87(4):801-809.

20. John U, Hanke M, Rumpf H-J, Thyrian JR. Smoking status, cigarettes per day, and their relationship to overweight and obesity among former and current smokers in a national adult general population sample. Int J Obes (Lond). 2005;29(10):1289-1294.

21. Anderson JW, Kendall CW, Jenkins DJ. Importance of weight management in type 2 diabetes: review with meta-analysis of clinical studies. J Am Coll Nutr. 2003;22(5):331-339.

22. Virdis A, GiannarelliC, Neves MF, Taddei S, Ghiadoni L. Cigarette smoking and hypertension. Curr Pharm Des. 2010;16(23):2518-2525.

23. Wee CC, Rigotti NA, Davis RB, Phillips RS. Relationship between smoking and weight control efforts among adults in the United States. Arch Intern Med. 2001;161(4):546-550.

\section{Dovepress}

metabolic disorders, particularly diabetes. This journal is indexed on PubMed Central and MedLine. The manuscript management system is completely online and includes a very quick and fair peer-review system, which is all easy to use. Visit http://www.dovepress.com/ testimonials.php to read real quotes from published authors. 